\title{
Varia
}

\section{Le groupe « HagHis » et les Vitae de saint Léger d'Autun}

Bruno Dumézil, Stéphane Gioanni et Charles Mériaux

\section{Q OpenEdition}

1 Journals

Édition électronique

URL : https://journals.openedition.org/cem/7232

DOI : $10.4000 /$ cem. 7232

ISSN : 1954-3093

Éditeur

Centre d'études médiévales Saint-Germain d'Auxerre

Édition imprimée

Date de publication : 15 août 2008

ISSN : 1623-5770

Référence électronique

Bruno Dumézil, Stéphane Gioanni et Charles Mériaux, « Le groupe « HagHis » et les Vitae de saint Léger d'Autun », Bulletin du centre d'études médiévales d'Auxerre | BUCEMA [En ligne], 12 | 2008, mis en ligne le 02 juillet 2008, consulté le 22 septembre 2022. URL : http://journals.openedition.org/cem/ 7232 ; DOl : https://doi.org/10.4000/cem.7232

Ce document a été généré automatiquement le 22 septembre 2022.

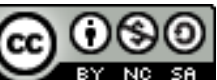

Creative Commons - Attribution - Pas d'Utilisation Commerciale - Partage dans les Mêmes Conditions 4.0 International - CC BY-NC-SA 4.0

https://creativecommons.org/licenses/by-nc-sa/4.0/ 


\title{
Le groupe « HagHis » et les Vitae de saint Léger d'Autun
}

\author{
Bruno Dumézil, Stéphane Gioanni et Charles Mériaux
}

1 Nous signalons la création d'un groupe de recherche sur l'hagiographie du haut Moyen Âge (HagHis), organisé par Bruno Dumézil, Stéphane Gioanni et Charles Mériaux, réunissant des philologues et des historiens. Les membres se réunissent plusieurs fois par an pour étudier le dossier hagiographique de saint Léger d'Autun et proposer une nouvelle traduction de la Passion. Nous avons commencé par traduire le fragment de la Vita de l'anonyme d'Autun - les seuls chapitres 23-37 de la Vita prima reconstituée par B. Krusch dans MGH SRM, t. V, p. 304-320 - avant d'aborder la Vita d'Ursin (ibid., p.323-356). L'ensemble permet non seulement de travailler sur le personnage historique de Léger, mais aussi d'aborder, à partir d'un cas précis, les problèmes de la réécriture hagiographique, puisque les deux Vies ont été fondues ensemble dans le courant du VIII siècle. Ce travail devrait déboucher prochainement sur une publication. Les réunions se tiennent chaque trimestre en Sorbonne (salle Perroy).

2 En complément, le groupe souhaite organiser des journées d'étude sur l'hagiographie du haut Moyen Âge, où seront conviés doctorants, chercheurs débutants et chevronnés, afin de confronter méthodes et problématiques de recherche. La première rencontre, le 27 janvier 2009, portera sur la Vie de saint Éloi. Ce document est capital pour notre connaissance de la royauté mérovingienne du VII siècle du fait de la personnalité de son sujet, monétaire de Clotaire II puis de Dagobert, devenu, à la mort du souverain (639), évêque de Noyon/Tournai. C'est également un texte essentiel pour l'histoire du genre hagiographique puisqu'il emprunte à un grand nombre de sources (bibliques et hagiographiques) et, en retour, servit de modèle à un très grand nombre de textes postérieurs. C'est enfin un document-clef pour l'histoire de la philologie : l'édition très partielle procurée par Bruno Krusch (1902), outre le fait qu'elle laisse de côté un manuscrit capital - TOURS, Bibliothèque municipale, 1028, du X $\mathrm{X}^{\mathrm{e}}$ siècle -, repose sur des présupposés et des choix aujourd'hui contestés. Le but de cette première rencontre est ainsi de faire le point sur un ensemble de problèmes philologiques et linguistiques, débattus depuis près d'un siècle - auteur, remanieur, sources utilisées, réception de 
l'œuvre - à la lumière des progrès considérables réalisés désormais grâce à une meilleure connaissance de la tradition manuscrite des œuvres médio-latines, à l'utilisation des banques de données textuelles, etc. Mais, il s'agira également d'examiner les implications que ces observations peuvent avoir sur notre connaissance d'Éloi, de la royauté et de l'épiscopat mérovingien.

3 Le calendrier et la présentation des travaux d'HagHis peuvent être consultés sur le site internet réalisé par Sylvie Joye : http://haghis.blogspot.com/2008/02/traduction-desvies-de-saint-lger.html.

INDEX

Index géographique : France/Autun

Mots-clés : vita, Léger d'Autun (saint) 